\title{
Influence of experimental feed additives on growth, development and productivity of young pigs
}

\author{
Alexander Gerasimovich ${ }^{1,}$, Vyacheslav Gogulov ${ }^{1}$, and Magomed Chabaev ${ }^{2}$ \\ ${ }^{1}$ Far Eastern State Agrarian University, 86, Politeknicheskaya Str., Blagoveschensk, Russia \\ ${ }^{2}$ L.K. Ernst Federal Science Center for Animal Husbandry, Moscow region, Podolsk, Dubrovitsy, \\ Russia
}

\begin{abstract}
Pig farming is one of the dynamically developing branches of animal husbandry. Of all the factors that determine the success of the livestock industry, the most important is biologically complete animal feeding, which makes it possible to realize the genetic potential of animals. Numerous scientific developments show that the use of local nontraditional feed additives in combination with probiotic and enzymatic preparations in pig feeding is currently promising. The geographical location of the Amur region makes it possible to widely use cheap seaweed in animal feeding. In the course of scientific research, scientists have already proven the effectiveness of feeding brown algae to animals. As for the red algae, the representative of which is anfeltia red, research on its use in pig feeding in the Amur region was conducted for the first time. Ahnfeltia red contains a small amount of regulated organic and biologically active substances. The aim of experimental studies was to study the effect of feeding red anfeltia separately and together with the enzymatic probiotic "Vitacell" on the metabolism and productivity of young pigs. In the process of conducting scientific and economic balance (physiological) experiments established that the inclusion in the feed of angelli red together with probiotic "of Vitacell" helped to increase average daily gains, increase the intensity of metabolic processes and to improve the fattening qualities of young pigs.
\end{abstract}

\section{Introduction}

One of the most important branches of animal husbandry at the present stage is pig farming, since the increase in meat production is mainly due to pork. Reducing the cost of production is possible only when biologically complete feeding of animals and the full realization of their genetic potential. One of the tasks of reforming agriculture in the Russian Federation is the transition to adapted technologies for its management based on the differentiated use of natural feed resources, taking into account the climatic and biogeochemical characteristics of each region. In this regard, the most promising and safe feed additives are made on the basis of natural raw materials. The Amur region is included

\footnotetext{
*Corresponding author: overvalera@gmail.com
} 
in the biogeochemical province, which is deficient in all normalized trace elements, which is from 30 to $90 \%$ of the national average. Cheap non-traditional feed of local origin can be used as a source of normalized biologically active substances in the Amur region. Such in the Amur region can be red algae and their alginates. [1]

Research conducted on the use of non-traditional feed resources of local origin in animal feeding is relevant. Russian and foreign scientists studied the use of natural feed resources in pig feeding. [2,3,4]

Biological feed additive "Vitacell" (Vitacell) - a concentrated enzyme-probiotic preparation obtained on the basis of solid - phase fermentation of microorganisms of cellulolytic, probiotic and prebiotic action (Ruminococcus albus and Lactobacillus sp, Bacillus subtilis 8130)-isolated from the gastrointestinal tract of ruminants (elk) and poultry (capercaillie). Contains a complex of enzymes with cellulolytic, amylolytic, proteolytic and beta gluconase activity, the filler is sunflower meal.

Taking into account that the main costs in pig farming are feed costs, feed efficiency is of particular, if not paramount, importance in commercial pig farming. Around the world, pig farming, along with other livestock industries, is moving towards limiting, and eventually completely banning, the use of antibiotics as growth promoters. Therefore, it is urgently necessary to choose an ideal alternative to feed antibiotics to compensate for the lost benefits due to the ban on their use for maintaining profitability and sustainable pig production [5]. In addition, probiotic microorganisms have the ability to synthesize a number of substances that improve the physiological state of the animal and increase its productive qualities.[6,7] these substances include organic acids that normalize the $\mathrm{pH}$ of the gastrointestinal tract, vitamins, and hydrolytic enzymes that increase the availability of feed nutrients. Probiotics can activate pancreatic enzymes, as well as the secretion of intestinal glands, deconjugation of bile acid salts, increase the resistance of the animal body, actively participate in metabolic processes and the construction of plastic material. [8] Morphological and biochemical blood tests show that all the studied parameters were within the limits of physiological values. At the same time, the blood of animals receiving probiotic drugs had a higher content of red blood cells, hemoglobin, total protein and its fractions, and vitamins. This indicates a more intensive course of redox reactions and the absence of inflammatory processes in animals treated with probiotic.[9,10,11]

The current direction of reducing the cost of livestock production, the safety of feed from replacing animal protein with vegetable protein (soy, sunflower, and others) has put forward a number of problems:

1. Low protein digestibility,

2. the Presence of anti-nutritional factors-non-starchy polysaccharides

3. Increasing the level of mycotoxins in feed. In addition, in the digestive tract of birds, pigs and young ruminants, there are no enzymes that break down complex non-starchy polysaccharides such as cellulose, hemicellulose, pentazanes, $\beta$-glucans, pectins and starch.[13]

Probiotics can also affect intestinal absorption and secretion in pigs. Studies show that the replacement of feed antibiotics with probiotic drugs is possible without reducing the productivity of farm animals and poultry. [14]

Numerous studies have shown that probiotics can improve the digestibility of dry matter, organic matter, raw protein, raw fiber, and phosphorus absorption.[15]

The inclusion of a probiotic drug in the diet of breeding young animals led to a maximum improvement in the slaughter indicators of podsvinkov: pre-slaughter and slaughter weight, slaughter yield by $2.2-11.1 \%(\mathrm{p}<0.05-0.001)$ respectively. According to the North Caucasus research Institute of animal husbandry, a probiotic drug can have a positive effect on the formation of microbiocenosis in the intestines of piglets, which contributes to their safety and overall efficiency of cultivation [16]. 
A number of authors note that the introduction of probiotic drugs does not have the same effect in different sex and age periods. Thus, the most effective results show the introduction of enzymatic probiotics and complex probiotic drugs in the suckling period. This makes it possible not only to improve the intensity of growth and development, but also to prevent gastrointestinal disorders, namely diarrhea $[17,18]$

\section{Materials and methods}

Scientific research was carried out on the basis of agro-S. E. V. LLC in the Konstantinovsky district of the Amur region. Scientific, economic and physiological experiments were conducted on young pigs in three age periods. In scientific and economic experiments there were 60 pigs divided by the principle of pairs of analogs into three groups, one control and two experimental. Young animals from the control group were fed full-fledged compound feed of the SPK brand in accordance with the age period, from 43 to 60 days - SPK-4, from 60 to 120 days - SPK-5 and from 121 to 240 days - SPK-10. For pigs from the first experimental group, $1 \%$ of the red anfeltion from the dry matter of the diet was included in the compound feed, and for animals from the second experimental group, the red anfeltion was included in a complex with $0.01 \%$ of the enzymatic probiotic "Vitacell" (table 1)

Table 1. Scheme of scientific and economic experience.

\begin{tabular}{|c|c|c|c|c|}
\hline \multirow{2}{*}{ Group } & \multirow{2}{*}{$\mathrm{n}$} & \multicolumn{3}{|c|}{ Age, days } \\
\hline & & $43-60$ & $61-120$ & $121-240$ \\
\hline Control & 20 & $\begin{array}{l}\text { The main diet of } \\
\text { SPK-4 }\end{array}$ & SPK-5 & SPK-10 \\
\hline 1 Experienced & 20 & $\begin{array}{l}\text { SPK- } 4+1 \% \text { anfel } \\
\text { red from dry matter }\end{array}$ & $\begin{array}{c}\text { SPK }-5+1 \% \text { anfel } \\
\text { red from dry } \\
\text { matter }\end{array}$ & $\begin{array}{l}\text { SPK- } 10+1 \% \text { anfel } \\
\text { red from dry matter }\end{array}$ \\
\hline 2 Experienced & 20 & $\begin{array}{l}\text { SPK-4 }+1 \% \text { red } \\
\text { anfeltion }+0.01 \% \\
\text { Vitacell probiotic } \\
\text { from dry matter }\end{array}$ & $\begin{array}{c}\text { SPK-5 + 1\% red } \\
\text { anfeltion }+0.01 \% \\
\text { probiotic } \\
\text { "Vitacell" from dry } \\
\text { matter } \\
\end{array}$ & $\begin{array}{l}\text { SPK- } 10+1 \% \text { red } \\
\text { anfeltion }+0.01 \% \\
\text { probiotic "Vitacell" } \\
\text { from dry matter }\end{array}$ \\
\hline
\end{tabular}

The chemical composition of compound feeds and metabolic products for the content of mineral elements in them was studied using the Unico 1201 digital spectrograph. In the physiological experiment, when determining the digestibility and assimilation of nutrients, the amount of feed consumed, its residues and excrement from each animal was taken into account every day. The content of organic substances in feed ingredients and excrement was determined using generally accepted methods of zootechnical analysis. The obtained data were processed using the methods of variation statistics. the reliability of the difference in comparison with the control group was determined using the student's t-test. In order to most fully track the influence of the studied factors in different age and gender periods, studies were conducted from weaning to the end of fattening and transfer to slaughter. 


\section{Results}

The results Obtained in the course of the conducted scientific and economic experience indicate a beneficial effect of experimental feed additives containing red anfel and the probiotic "Vitacel" on the change in the live weight of young pigs (table. 2)

Table 2. Dynamics of live weight of young pigs, $\mathrm{M} \pm \mathrm{m}$.

\begin{tabular}{|l|c|c|c|}
\hline \multirow{2}{*}{ Indicator } & \multicolumn{3}{c|}{ Group } \\
\cline { 2 - 4 } age from 43 to 60 days \\
\hline \multicolumn{1}{|c|}{ control } & 1 experienced & 2 experienced \\
\hline $\begin{array}{l}\text { Live weight at the beginning of the period, } \\
\mathrm{kg}\end{array}$ & $10.9 \pm 0.75$ & $10.89 \pm 0.74$ & $10.88 \pm 0.71$ \\
\hline Live weight at the end of the period, kg & $15.7 \pm 0.50$ & $16.2 \pm 0.63$ & $17.9 \pm 0.72$ \\
\hline Average daily growth, g & $282 \pm 9.2$ & $312 \pm 8.4$ & $412 \pm 10.5^{*}$ \\
\hline $\begin{array}{l}\text { Average daily increase in \% of the control } \\
\text { group }\end{array}$ & 100 & 110 & 146 \\
\hline \multicolumn{1}{|c|}{ age from 61 to 120 days } \\
\hline $\begin{array}{l}\text { Live weight at the beginning of the period, } \\
\text { kg }\end{array}$ & $15.7 \pm 0.50$ & $16.2 \pm 0.63$ & $17.9 \pm 0.72$ \\
\hline Live weight at the end of the period, kg & $34.6 \pm 1.06$ & $35.9 \pm 1.96$ & $39.3 \pm 1.78$ \\
\hline Average daily growth, g & $320 \pm 12.4$ & $333 \pm 13.01$ & $362 \pm 11.7 *$ \\
\hline $\begin{array}{l}\text { Average daily increase in \% of the control } \\
\text { group }\end{array}$ & 100 & 104 & 113 \\
\hline & \multicolumn{2}{|c|}{ age from 121 to 240 days } \\
\hline $\begin{array}{l}\text { Live weight at the beginning of the period, } \\
\text { kg }\end{array}$ & $34.6 \pm 1.06$ & $35.9 \pm 1.96$ & $39.3 \pm 1.78$ \\
\hline Live weight at the end of the period, kg & $107.9 \pm 2.95$ & $111.3 \pm 3.66^{*}$ & $121.05 \pm 3.18$ \\
\hline Average daily growth, g & $615 \pm 24.4$ & $634 \pm 33.5$ & $687 \pm 25.9$ \\
\hline $\begin{array}{l}\text { Average daily increase in \% of the control } \\
\text { group }\end{array}$ & 100 & 103 & 112 \\
\hline
\end{tabular}

125

120

115

111.3

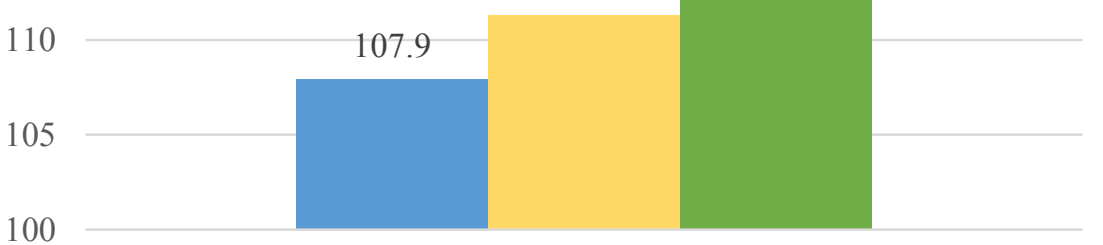

The live weight. $\mathrm{kg}$

\section{-Control group $\square 1$ Experimental group $\square 2$ Experimental group}

Fig.1. Live weight of fattening pigs at the end of scientific and economic experience.

The table shows that at the beginning of the scientific and economic experiment, the average live weight of young pigs was the same, but at the end of the entire experimental period, there were differences between the groups. The best indicators were observed in the 
second experimental group, when the main diet included $1 \%$ anfel red and $0.01 \%$ probiotic in terms of the dry substance of the diet. It should be noted that the greatest effect from the introduction of experimental feed additives is observed in the age period from 43 to 60 days. In our opinion, this is due to the fact that at this age period the digestive system of young pigs is not yet fully formed, and the additional introduction of a probiotic drug into the diet had an auxiliary effect on the digestive processes. Thus, the average daily increase in the second experimental group for this period was 412 grams per day, which is $46 \%$ higher than this indicator in the control group. With age, the effect of experimental feed additives decreases, but pigs of the first and second experimental groups still significantly outperform their peers from the control group by $4 \%$ and $13 \%$ in the second period and by $3 \%$ and $12 \%$ in the third period, respectively.

At the age of 60 and 121 days, physiological experiments were conducted. The coefficients of digestibility of organic substances of experimental compound feeds were higher in comparison with the control group (table 3 )

Table 3. Nutrient digestibility Coefficients, $\%$.

\begin{tabular}{|l|c|c|c|c|}
\hline \multirow{2}{*}{ Group } & \multicolumn{4}{c|}{ Indicator } \\
\cline { 2 - 5 } & Crude protein & Crude fat & Crude fiber & NFES \\
\hline \multicolumn{2}{|c|}{ The first physiological experience } \\
\hline Control & 64.9 & 46.6 & 24.5 & 79.9 \\
\hline 1 experienced & 71.0 & 50.6 & 25.0 & 82.4 \\
\hline 2 experienced & 72.5 & 52.5 & 29.8 & 86.2 \\
\hline The second physiological experience \\
\hline Control & 70.5 & 50.1 & 30.8 & 82.1 \\
\hline 1 experienced & 73.3 & 50.4 & 31.5 & 83.5 \\
\hline 2 experienced & 74.2 & 51.4 & 33.8 & 84.6 \\
\hline
\end{tabular}

The protein digestibility of the diet in the control group animals in the first period was $64.9 \%$, and in the second period $70.5 \%$. The inclusion of red anfel in the diet increases the protein digestibility in the first study period by $6.1 \%$ and in the second by $2.8 \%$. In the second experimental group, where the animals in the diet were additionally introduced an experimental Supplement from anfel red together with the probiotic drug "Vitacell", there was a more significant increase in this indicator relative to the control group. Thus, the protein digestibility index in the second experimental group in the first period of the experiment was $72.5 \%$, and in the second period $74.2 \%$, which is $7.6 \%$ and $3.7 \%$, respectively, more than similar indicators in the control group.

This dynamic is also observed in crude fat, crude fiber, and nitrogen-free extractives. It should be noted that the best indicators for the digestibility of nutrients are noted in the second experimental group.

Changes in animal productivity under the influence of the studied factor occur not only due to changes in the digestibility of feed nutrients, but also due to changes in the efficiency of their use by the body. All types of metabolism - carbohydrate, mineral and nucleic provide protein metabolism, which is the relationship between mineral and protein nutrition. The study of protein metabolism is usually carried out according to its balance, which characterizes the biological fullness of feed rations fed to animals, the degree of use of nitrogenous substances of feed. Therefore, the creation of conditions for the maximum use of nitrogen feed animals is a necessary factor for their high productivity.

The amount of proteins received in the animal's body and used can be judged by the amount of nitrogen exchange.

It is obvious that the need for pigs in minerals is directly dependent on the type and composition of the diet, the ratio of nutrients and biologically active substances, the 
availability of minerals and their relationships. One of the most important indicators that characterize the metabolism of animals and their availability of minerals is the balance of calcium and phosphorus.

The balance and use of nitrogen, calcium, and phosphorus is shown in the table (table 4).

Table 4. Balance and use of nitrogen, calcium and phosphorus, g.

\begin{tabular}{|c|c|c|c|}
\hline \multirow[t]{2}{*}{ Indicator } & \multicolumn{3}{|l|}{ Group } \\
\hline & control & 1 experienced & 2 experienced \\
\hline \multicolumn{4}{|c|}{ Nitrogen } \\
\hline Taken with food & 76.82 & 77.04 & 76.94 \\
\hline Highlighted with feces & 32.10 & 32.07 & 32.28 \\
\hline Excreted in urine & 11.01 & 10.95 & 10.55 \\
\hline Balance & 33.71 & 34.02 & 34.11 \\
\hline Used from accepted, $\%$ & $43.88 \pm 1.14$ & $44.15 \pm 0.89$ & $44.33 \pm 0.96$ \\
\hline \multicolumn{4}{|c|}{ Calcium } \\
\hline Taken with food & 24.63 & 24.59 & 24.60 \\
\hline Highlighted with feces & 17.23 & 17.01 & 16.94 \\
\hline Excreted in urine & 0.40 & 0.38 & 0.37 \\
\hline Balance & 7.00 & 7.20 & 7.29 \\
\hline Used from accepted, $\%$ & $28.42 \pm 1.26$ & $29.28 \pm 1.17$ & $29.63 \pm 0.98$ \\
\hline \multicolumn{4}{|c|}{ Phosphorus } \\
\hline Taken with food & 16.52 & 16.50 & 16.51 \\
\hline Highlighted with feces & 10.20 & 10.10 & 9.95 \\
\hline Excreted in urine & 0.35 & 0.29 & 0.28 \\
\hline Balance & 5.97 & 6.11 & 6.28 \\
\hline Used from accepted, $\%$ & $36.13 \pm 2.21$ & $37.03 \pm 2.18$ & $38.03 \pm 1.85$ \\
\hline
\end{tabular}

The results show that the balance of nitrogen, calcium and phosphorus in all groups was positive. Physiological experience has shown that the feed intake of nitrogen, calcium and phosphorus in all groups was the same. The difference between the groups in the assimilation of these elements, in our opinion, may be related to the more effective use of feed due to the introduction of experimental additives. The most effectively digested nitrogen was used by animals from the second experimental group, when including red anfeltia and probiotic drug in the diet. This is evidenced by the highest level of nitrogen absorption $-44.33 \%$, and the highest average daily increase-687 grams per head per day.

Studies on the balance and use of calcium and phosphorus in the body show that experimental feed additives, although slightly, but improve the digestibility of these elements. Thus, calcium absorption in the first and second experimental groups exceeded control animals by $0.86 \%$ and $1.21 \%$, respectively. A similar pattern was observed when studying the absorption of phosphorus in the body of experimental animals.

When studying morphological and biochemical parameters of blood, deviations from the physiological norm were not observed in young animals of the experimental and control groups (table 5). At the end of the experiment at the age of eight months, the blood values of fattened boars, without going beyond the physiological norm, in all experimental groups approached the maximum physiological norm.

The obtained results of biochemical and hematological parameters of blood are generally comparable with the increase in live weight gain and correlate well with the data on nitrogen balance in the body of experimental animals. The highest indicators, without going beyond the physiological norm, are noted in the second experimental group. Thus, the increase in hemoglobin content in the second experimental group compared to control animals was $5.4 \%$, and the total protein content increased by $3.1 \%$. As a result of the 
experiment, it was noted that the introduction of anfel red together with the enzymatic drug "Vitacell" led to a decrease in the number of white blood cells by $3 \%$.

Table 5. Hematological and biochemical composition of blood.

\begin{tabular}{|l|c|c|c|}
\hline \multirow{2}{*}{\multicolumn{1}{|c|}{ Indicator }} & \multicolumn{3}{|c|}{ Group } \\
\cline { 2 - 4 } & control & 1 experienced & 2 experienced \\
\hline Hemoglobin, g/1 & $96.7 \pm 0.67$ & $100.00 \pm 1.15$ & $102.00 \pm 1.15$ \\
\hline Red blood cells, $10^{12} / 1$ & $6.51 \pm 0.02$ & $6.64 \pm 0.04$ & $6.94 \pm 0.07$ \\
\hline White blood cells, $10^{9} / 1$ & $12.03 \pm 0.03$ & $12.02 \pm 0.20$ & $11.68 \pm 0.10$ \\
\hline Total protein, g/1 & $77.40 \pm 0.83$ & $77.77 \pm 0.35^{*}$ & $79.87 \pm 0.42^{*}$ \\
\hline Calcium, $\mathrm{mmol} / 1$ & $2.53 \pm 0.03$ & $2.55 \pm 0.03$ & $2.62 \pm 0.02^{*}$ \\
\hline Phosphorus, $\mathrm{mmol} / 1$ & $2.22 \pm 0.04$ & $2.18 \pm 0.07$ & $2.19 \pm 0.03$ \\
\hline
\end{tabular}

At the end of the scientific and economic experiment, the slaughter qualities of pigs were studied, three heads from each group were slaughtered in accordance with the method (table 6). the table shows that the heavier carcass was obtained from the boars of the second experimental group, which were additionally introduced into the diet $1 \%$ anfel red and $0.01 \%$ of the enzymatic drug "Vitacell" in terms of the dry substance of the diet.

Table 6. Results of control slaughter of young pigs.

\begin{tabular}{|l|c|c|c|}
\hline \multirow{2}{*}{\multicolumn{1}{|c|}{ Indicator }} & \multicolumn{3}{c|}{ Group } \\
\cline { 2 - 4 } & control & 1 experienced & 2 experienced \\
\hline Pre-slaughter weight, $\mathrm{kg}$ & $105.80 \pm 0.90$ & $109.50 \pm 1.36^{* *}$ & $119.20 \pm 0.97^{* *}$ \\
\hline Slaughter weight, $\mathrm{kg}$ & $68.9 \pm 2.54$ & $72.9 \pm 1.94^{* *}$ & $79.3 \pm 1.48^{*}$ \\
\hline Killer exit, \% & $65.2 \pm 4.24$ & $66.6 \pm 3.87^{* *}$ & $66.5 \pm 4.01^{*}$ \\
\hline Backfat thickness, mm & $32.3 \pm 2.79$ & $32.1 \pm 1.83$ & $32.1 \pm 1.48$ \\
\hline Internal fat mass, kg & $1.9 \pm 0.12$ & $1.71 \pm 0.12^{*}$ & $1.65 \pm 0.1 *$ \\
\hline Ham weight. kg & $10.8 \pm 0.86$ & $11.5 \pm 0.74$ & $12.2 \pm 0.92$ \\
\hline
\end{tabular}

The results of control slaughter show that experimental feed additives introduced into the diets of experimental groups contribute to an increase in the growth rate, and, consequently, to an increase in the slaughter mass. Thus, the slaughter weight of young animals from the first and second experimental groups exceeded their peers from the control group by $3.5 \%$ and $12.6 \%$, respectively, for the same period of fattening. However, it should be noted that the difference in slaughter yield between all groups is not significant. We assume that this is due to the limitation of the genetic potential of the studied animals. The thickness of the lard in all groups was also at the same level.

\section{Discussion}

Among biologically active substances, the most common means of maintaining the microecology of animals are probiotic feed additives, which are preparations in the form of live strains of microorganisms that can stimulate the development and maintenance of useful microflora of the gastrointestinal tract and are producers of highly valuable complexes of biologically active substances for the body. Taking into account the improvement of metabolism, physiological and biochemical processes occurring in the body, this has a positive effect on the intensity of growth of animals and the quality of the resulting products. The conducted research shows that the introduction of probiotic drug 
into pig feed had a positive effect on the growth rate and metabolic processes of experimental animals. [19]

The worldwide refusal to use feed antibiotics has only spurred interest in the study of alternative growth stimulants, and probiotic and enzyme preparations make it possible to obtain more environmentally friendly products. These studies are particularly important in regions where the feed base, including the components of compound feeds, consists exclusively of products of their own production. A modern approach to the formation of mixed feed recipes in such areas will increase the cost of production, and most importantly, provide the population with safe, environmentally friendly products.

\section{Conclusions}

The results of the research show that the best indicators for absolute and average daily increase in live weight in pigs were observed in animals that were fed red anfeltion together with the enzymatic drug "Vitacell". The introduction of this experimental feed additive made it possible to obtain an additional 13.15 kilograms of live weight per head $(\mathrm{P}<0.05)$ at the end of the experiment.

Research on the introduction of probiotic drugs into the diets of animals and poultry together with non-traditional feed products used in the Far East (such as sapropel humates, soy protein asparaginates, etc.) is relevant and of great scientific and practical interest.

\section{References}

1. R. L. Sharvadze, T. A. Krasnoshchekova, L. I. Perepelkina, V. V. Samuylo, Y. B. Kurkov Use of chelated formsof microelements contained in natural food resources in feeding animals within the territory of the Amur Riverregion EurAsian Journal of BioSciences. 12(1), 143-148 (2018)

2. J. R. Pluske, D. L. Turpin, J.-C. Kim Gastrointestinal tract (gut) health in the young pig Animal Nutrition, 4 (2), pp. 187-196. doi: 10.1016/j. aninu. 2017.12. 004 (2018)

3. B.P. Willing, G. Malik, A.G. Van Kessel, Nutrition and Gut Health in Swine Sustainable Swine Nutrition, 197-213. ISBN: 978-081380534-4 (2012) doi: 10.1002/9781118491454.ch8

4. 4.G.D. Xue, R. Barekatain, S.B. Wu, M. Choct, R.A. Swick, Dietary L-glutamine supplementation improves growth performance, gut morphology, and serum biochemical indices of broiler chickens during necrotic enteritis challenge, 97 (4), 1334-1341 (2018) Poultry Science,. doi: 10.3382/ps/pex444

5. S.F. Liao, Nyachoti, M.Using probiotics to improve swine gut health and nutrient utilization 3 (4), 331-343. (2017) doi: 10.1016/j.aninu.2017.06.007

6. O. Rudisin Influence of the probiotic "Rivestimento" on the growth rate and the indicators of control slaughter of young pigs Pig breeding, 7, 44-45 (2010)

7. T. A. Shamilova, N. M. Shamilov Study of probiotic effectiveness in experiments on pigs Scientific notes of the Kazan state Academy of veterinary medicine named after N. E. Bauman, 211, 337-340 (2012)

8. P. Fajardo, L. Pastrana, J. Mendez, I. Rodriguez, C. Fucinos, N..P Guerra Effects of feeding of two potentially probiotic preparations from Lactic Acid Bacteria on the performance and faecal microflora of broiler chickens. Scient. (2012). World J.2012:562635. https://doi.org/10.1100/2012/562635 
9. M. Kenny, H. Smidt, E. Mengheri, B. Miller, Probiotics-do they have a role in the pig industry? Animal, 5 (3), 462-470 (2011) doi: 10.1017/S175173111000193X

10. D. Józefiak, S. Kaczmarek, A. Rutkowski "A note on the effects of selected prebiotics on the performance and ileal microbiota of broiler chickens", Journal of Animal and Feed Sciences, 17, 3, 392-397 (2008)

11. G.D. Xue, R. Barekatain, S.B. Wu, M. Choct, R.A. Swick "Dietary L-glutamine supplementation improves growth performance, gut morphology, and serum biochemical indices of broiler chickens during necrotic enteritis challenge", Poultry science, 97, 4, 1334-1341 (2018)

12. T. Wang, K. Teng, Y. Liu, W. Shi, J. Zhang, E. Dong, X. Zhang, Y. Tao Lactobacillus plantarum PFM 105 promotes intestinal development through modulation of gut microbiota in weaning piglets", Frontiers in Microbiology, 10 (2019)

13. I. F. Gorlov, V. A. Baranikov, N. A. Yurina, N. A. Omelchenko, E. A. Maxim Productive action of a complex of probiotic additives Agrarian scientific journal, 11, 17-20 (2014)

14. R. Suárez, N. Buitrago "Probiotic supplementation with Lactobacillus casei in sows and its effects on the zootechnical parameters of piglets", Revista de Investigaciones Veterinarias del Peru, 30, 2, 645-654 (2019)

15. H. Reyer, M. Oster, U. M. McCormack, E. Muráni, G. E. Gardiner \& Wimmers, K. 2020, "Host-microbiota interactions in ileum and caecum of pigs divergent in feed efficiency contribute to nutrient utilization", Microorganisms, 8, 4 (2020)

16. D. V. Osepchuk Experience of using solid palm fats in diets for young pigs SB. nauch. Tr. Stavropol research Institute of animal husbandry and feed production 3, 1.145-148 (2012)

17. K. Cui, Q. Wang, S. Wang, Q. Diao "The facilitating effect of tartary buckwheat flavonoids and lactobacillus plantarum on the growth performance, nutrient digestibility, antioxidant capacity, and fecal microbiota of weaned piglets", Animals, 9, 11 (2019)

18. H. Quesnel, C. Farmer "Review: Nutritional and endocrine control of colostrogenesis in swine", Animal, 13, S1, S26-S34 (2019)

19. Z. Yang, \& S.F. Liao"Physiological effects of dietary amino acids on gut health and functions of swine", Frontiers in Veterinary Science, 6, JUN (2019) 